\title{
Dynamic-mechanical properties as a function of luffa fibre content and adhesion in a polyester composite
}

\author{
G. Kalusuraman a, I. Siva ${ }^{\text {a,b, }}$, Yashwant Munde ${ }^{c}$, Chithirai Pon Selvan ${ }^{\text {d }}$, S. Anand Kumar ${ }^{\text {, }}$ \\ Sandro C. Amico ${ }^{b}$ \\ ${ }^{\text {a }}$ Centre for Composite Materials, Kalasalingam Academy of Research and Education, Anand Nagar, TN, India \\ ${ }^{\mathrm{b}}$ PPGEM, Universidade Federal Rio Grande do Sul, Porto Alegre, RS, Brazil \\ ${ }^{\mathrm{c}}$ Department of Mechanical Engineering, Cummins College of Engineering for Women, Pune, MH, India \\ ${ }^{\mathrm{d}}$ School of Science and Engineering, Curtin University Dubai, United Arab Emirates \\ e Department of Mechanical Engineering, Indian Institute of Technology-Jammu, $J \&$ K, 181221, India
}

\section{A R T I C L E I N F O}

\section{Keywords:}

Polyester composites

Fibre treatment

Dynamic-mechanical properties

\begin{abstract}
A B S T R A C T
In this work, the characteristics of a vegetable fibre (luffa cylindrica) polyester composite are studied as a function of fibre surface treatment (with $\mathrm{NaOH}, \mathrm{Ca}(\mathrm{OH})_{2}$ and silane) and fibre content (30\%, 40\% and 50\%). Composites were prepared through compression moulding and characterized with thermogravimetric and dynamic-mechanical analyses. Higher storage modulus was obtained with $\mathrm{Ca}(\mathrm{OH})_{2}$ treated composites, reaching nearly 70\% increase. Higher loss modulus (E”) was noted in for silane treated fibre (at 50\%) and a high peak in damping factor was noted for $\mathrm{Ca}(\mathrm{OH})_{2}$ treated fibre (at 50\%). Cole-cole plot showed highest homogeneity for the $\mathrm{Ca}(\mathrm{OH})_{2}$ treated composites. Electron microscopy revealed the fracture modes in static tested composites. The general properties obtained indicate that the composites can only be used for low loading applications.
\end{abstract}

\section{Introduction}

Natural fibres have drawn the attention of researchers as potential substitutes for synthetic fibres. These fibres have specific mechanical properties somewhat comparable to those of synthetic fibres [1]. Other benefits include abundance, low cost, low density, non-toxicity, recyclability and reduced waste disposal problems. Natural fibre reinforced composites find potential applications in sectors such as automobiles and in civil engineering [2,3], Early studies on luffa cylindrica fiber have reported its possible use for water absorption [4] and waste water treatment [5] and also as reinforcement for composite materials, sometimes after a chemical treatment [4-6]. Alkali treatment of fibres are common for the partial removal of lignin and hemicellulose, increasing hydrophobicity $[7,8]$ and modifying its crystalline structure [9].

Interaction and inter-locking between luffa cylindrica fruit fibre were enhanced through fibre surface activation due to surface roughness and hydrophilicity [10] Thermal degradation behavior was mainly influenced by the degree of cross-linking in the produced composites. Breaking of chemical bonds inside the polymer system, eventually between fibre and matrix, and thermal degradation were also observed in treated composites. Surface treatment of fibres increased the relative cellulose content in the fibre, which is supposed to postpone thermal degradation $[11,12]$ and influence the composite properties. A previous study of the group [13], focused on mechanical and tribological properties of untreated and alkali-treated luffa fibre composites, reporting the benefit of mercerization in static property enhancement.

Theoretical modeling of fibre reinforced structures usually challenges the researchers due to heterogeneity. Several theories have been employed to predict their static and dynamic response, including the equations developed by Ref. [14] Guth [15] Cohan [16], Mooney [17]. Doddi et al. [18] studied that dynamic mechanical properties of hybrid pineapple leaf (PALF) and basalt fibre reinforced epoxy composite at variable vibration frequencies and reported that fibre orientation played a major role in dynamical properties. Senthilkumar et al. [19] reported that polyester composites with treated pineapple leaf fibre showed good improvement in dynamics properties. Kalusuraman et al. [20] studied untreated luffa fibre reinforced composites and reported significant increase in storage modulus of the composites with fibre content increase. Karthikeyan et al. [21] reported Dynamic properties on basalt-vinyl

\footnotetext{
* Corresponding author. Centre for Composite Materials, Kalasalingam Academy of Research and Education, Anand Nagar, TN, India.

E-mail address: isiva@klu.ac.in (I. Siva).
} 
Table 1

Chemical Properties of untreated Luffa fibre.

\begin{tabular}{ll}
\hline Property & Value \\
\hline Wax content (\%) & 0.48 \\
Moisture content (\%) & 9.75 \\
Cellulose content (\%) & 73.92 \\
Ash content (\%) & 4.74 \\
Density at room temperature (g/cc) & 1.31 \\
\hline
\end{tabular}

Table 2

Properties of polyester.

\begin{tabular}{ll}
\hline Property & Value \\
\hline Density at $25{ }^{\circ} \mathrm{C}(\mathrm{g} / \mathrm{cc})$ & $1.1-1.11$ \\
Tensile strength $(\mathrm{MPa})$ & $33.5-70$ \\
Tensile modulus $(\mathrm{GPa})$ & $1.0 \pm 0.40$ \\
Elongation at break $(\%)$ & $0.5-5$ \\
Flexural strength $(\mathrm{MPa})$ & $76-120$ \\
Izod Impact, notched $(\mathrm{J} / \mathrm{cm})$ & $0.15-3.2$ \\
\hline
\end{tabular}

ester tailor-made green composites with uncoated and polytetrafluroethylene coated basalt woven fabric and concluded that significance improvement in dynamics properties for coated samples.

The current work focuses on the study of the mechanical, thermal and dynamic-mechanical response of luffa/polyester composites with respect to fibre content and surface adhesion.

\section{Experimental}

\subsection{Materials and processing}

Luffa fibres were collected from agriculture fields in Southern Tamilnadu, India. The resin system was based on unsaturated polyester (USP - General purpose grade: SBA2303) with methyl-ethyl-ketone peroxide (MEKP) and cobalt-naphthenate as initiator and accelerator, respectively. Sodium hydroxide and calcium hydroxide, from Modern
Scientific (Madurai, India), and tri-chloro-vinyl silane, from SigmaAldrich (Bangalore, India), were used for fibre treatment.

Table 1 shows some characteristics of the luffa fibre and Table 2 shows the properties of unsaturated polyester resin. The fibre is rich in cellulose and has a significant wax content, which may be removed with alkali treatment. Moisture content is high and density is low compared to E-glass fibre, as expected.

Mercerization of the fibres was carried out by first washing and drying the fibres and then immersing them in $1 \mathrm{~N} \mathrm{NaOH}$ aqueous solution for $1 \mathrm{~h}$ followed by thorough washing using distilled water. Treated fibres were dried in an oven for $6 \mathrm{~h}$ at $60^{\circ} \mathrm{C}$. Part of these fibres was further treated with $1 \mathrm{~N} \mathrm{Ca}(\mathrm{OH})_{2}$ solution for $1 \mathrm{~h}$ followed by thorough washing with distilled water until neutral $\mathrm{pH}$ was reached [22]. And some art of the mercerized fibres was dipped into a silanol solution for $1 \mathrm{~h}$ followed by oven drying [22] The silanol solution was prepared by diluting $0.3 \mathrm{wt} \%$ of tri-chloro-vinyl silane in $1 \mathrm{~L}$ of acidified water $(3.5 \mathrm{pH})$.

Accelerated USP resin was deposited into the inner mold cavity, prepressed luffa mats were layered on top of it and more resin was placed on top each fibre layer. Finally, the mold was closed and kept at $15 \mathrm{MPa}$ for $4 \mathrm{~h}$ at room temperature. The cured composite was later removed from the mold and post-cured at $60{ }^{\circ} \mathrm{C}$ for $4 \mathrm{~h}$. Composites with three fibre weight contents (30-50\%) were studied. The nomenclature adopted includes a letter corresponding to the fibre treatment used, that is, $\mathrm{U}$ for untreated, $\mathrm{N}$ for $\mathrm{NaOH}, \mathrm{C}$ for $\mathrm{Ca}(\mathrm{OH})_{2}$ and $\mathrm{S}$ for tri-chloro-vinyl silane.

\subsection{Characterization}

All treated fibres were analysed using Fourier transform infrared spectroscopy (FTIR- IR Tracer-100 Shimadzu make) and scanning electron microscopy (SEM-Carl Zeiss - EVO18 with EDX spectrometer). Three-point bending test of the composites was conducted based on ASTM D790 in a universal testing machine Deepak Polyplast, with 3-ton load cell, and a span:thickness ratio of 16:1. Short-beam strength was evaluated as per ASTM D2344 with span:thickness ratio of 4:1. Unnotched impact strength of the composites was evaluated in a digital controlled impact tester as per ASTM D256. Shore D hardness of the composites was also evaluated. In all tests, averages of five

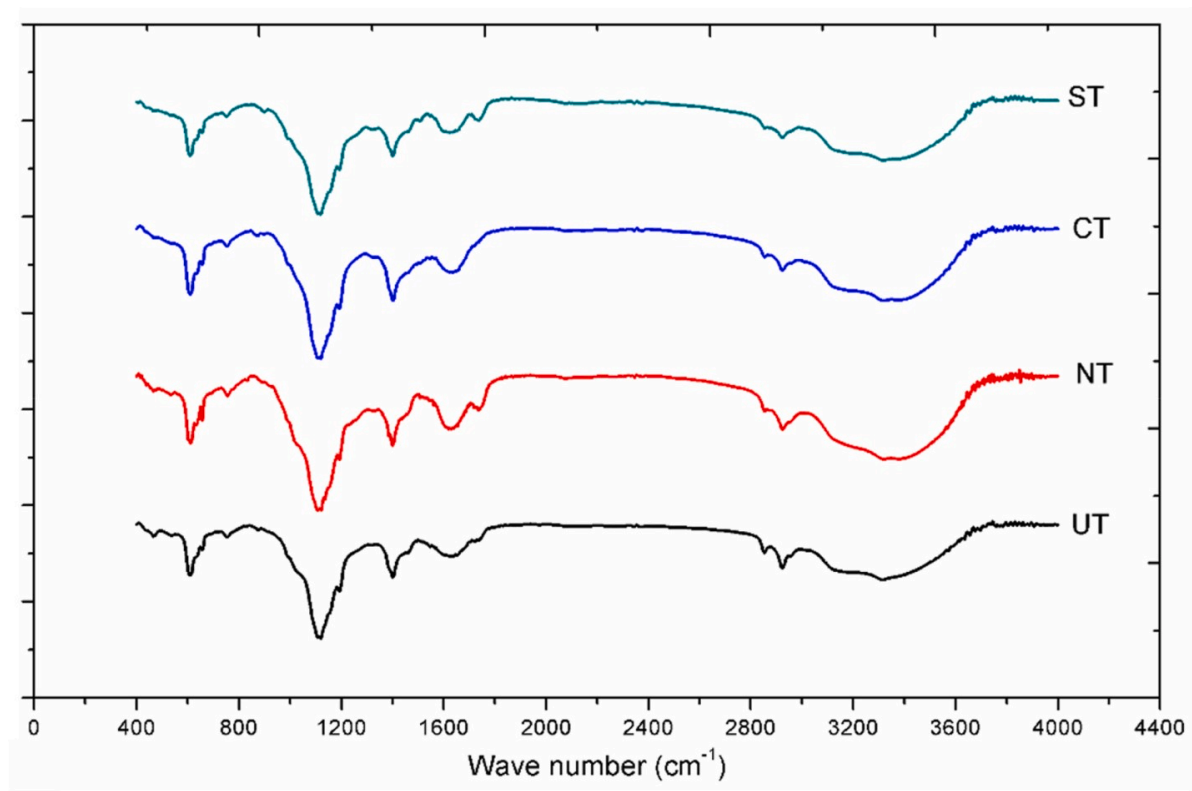

Fig. 1. FTIR spectra of the luffa fibres: untreated (UT), $\mathrm{NaOH}$ treated $(\mathrm{NT}), \mathrm{Ca}(\mathrm{OH})_{2}$ treated (CT) and silane treated (ST). 

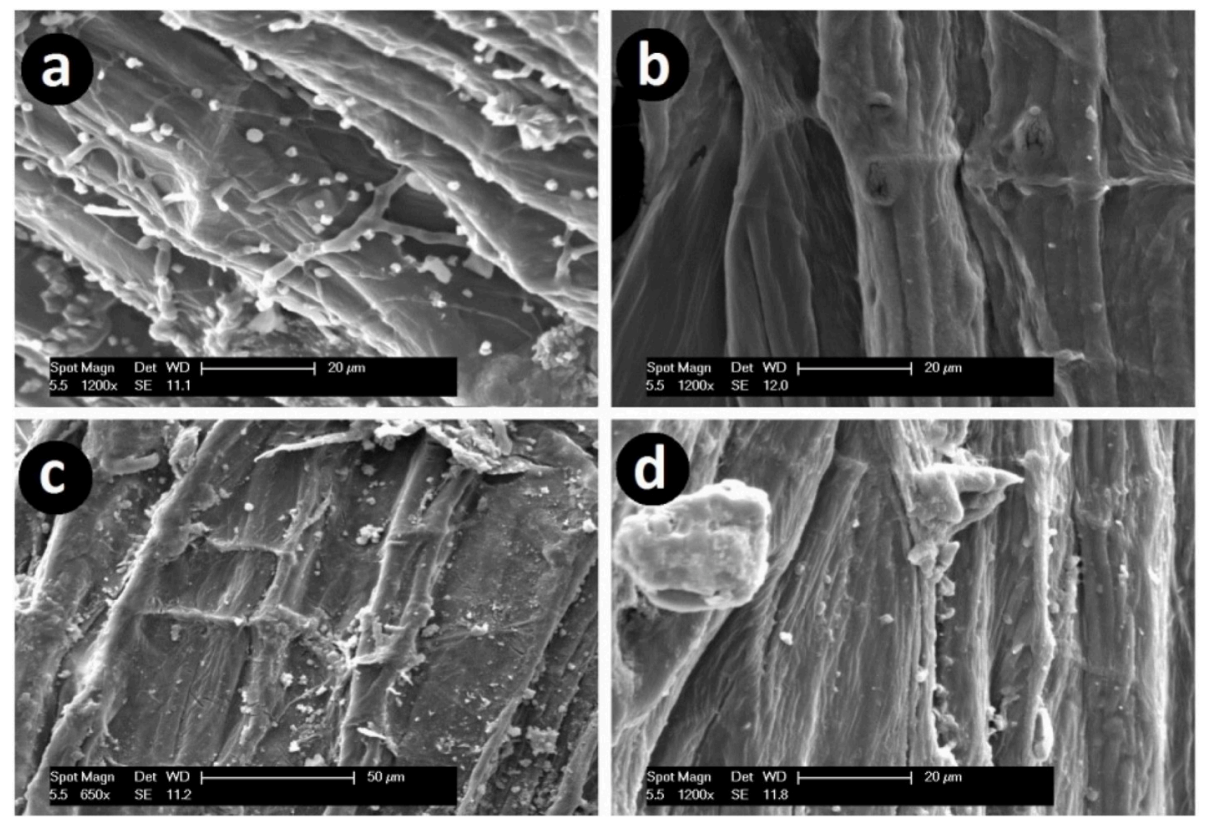

Fig. 2. Fibre morphology: Untreated (a), $\mathrm{NaOH}$ treated (b), $\mathrm{Ca}(\mathrm{OH})_{2}$ treated (c) and silane treated (d) luffa fibres.

Table 3

Fibre content, hardness and density of the composites.

\begin{tabular}{llll}
\hline Sample code & Fibre wt. (\%) & Hardness (Shore D) & Density (g/cc) \\
\hline U3 & 30 & 69 & 1.819 \\
U4 & 40 & 71 & 1.693 \\
U5 & 50 & 74 & 1.511 \\
N3 & 30 & 72 & 1.733 \\
N4 & 73 & 1.581 \\
N5 & 50 & 73 & 1.413 \\
C3 & 30 & 72 & 1.752 \\
C4 & 40 & 74 & 1.514 \\
C5 & 50 & 74 & 1.442 \\
S3 & 30 & 73 & 1.832 \\
S4 & 40 & 73 & 1.751 \\
S5 & 50 & 75 & 1.633 \\
\hline
\end{tabular}

measurements are reported.

Rectangular specimens $\left(60 \times 10 \times 3 \mathrm{~mm}^{3}\right)$ were studied in a dynamic-mechanical-thermal analyzer (Netzsch DMA 242) under three point-bending mode. The temperature range was $20-250{ }^{\circ} \mathrm{C}$, with a heating rate of $2{ }^{\circ} \mathrm{C} / \mathrm{min}$ and at a frequency of $1 \mathrm{~Hz}$. TGA (thermalgravimetric analysis) was done in the composites as per ASTM E1131. Samples were tested in powder form, from room temperature to 1000 ${ }^{\circ} \mathrm{C}$, with a heating rate of $20^{\circ} \mathrm{C} / \mathrm{min}$ under Nitrogen atmosphere using a DSC Q20 TA Instrument.

\section{Results and discussion}

\subsection{Fibre characterization}

Fig. 1 shows the FTIR spectra of untreated and treated luffa fibres. The untreated fibres exhibited absorption bands within 2800-2900 $\mathrm{cm}^{-1}$ due to aliphatic C-H stretching vibrations indicating the presence of alkyl chains [13]. The band at $1737 \mathrm{~cm}^{-1}$ is due to acid carbonyl absorption and the bands within $1100-1200 \mathrm{~cm}^{-1}$ indicate C-O-C stretching of polyester of the composite. The bands within 3200-3400 $\mathrm{cm}^{-1}$ are due to $\mathrm{O}-\mathrm{H}$ stretching vibrations of hydroxyl groups in the polyesters. $\mathrm{NaOH}$ and $\mathrm{Ca}(\mathrm{OH})_{2}$ treated fibres do not show strong absorption at $1737 \mathrm{~cm}^{-1}$ probably due to salt formation in the carboxylate group with sodium and calcium, respectively. Silane treated fibres, however, did not evidence any alteration compared to the mercerized fibre, suggesting no structural change in the organic part of the luffa fibres.

Fig. 2 shows the surface morphology of the luffa fibres. Fig. 2a shows, for untreated fibres, many impurities on the fibre surface. Fig. $2 \mathrm{~b}$ shows the surface of $\mathrm{NaOH}$ treated luffa fibre, and a cleaner and rougher surface is noticed. The $\mathrm{Ca}(\mathrm{OH})_{2}$ treated fibre (Fig. 2c) appears even rougher, whereas silane treated fibre (Fig. 2d) is smoother than the other two treated fibres due to some degree of silane coating.

\subsection{Composite properties}

Table 3 depicts the hardness values of the composites, and an increasing trend is found for higher fibre content, especially for the untreated composites. For the treated fibres, not much variation was noticed with fibre content or treatment. On the other hand, density of the composites clearly decreased with the increase in fibre content. $\mathrm{NaOH}$ treated fibre composites displayed the lowest density, whereas silane treated fibre composites yielded the highest values, perhaps due to a lower void content.

Fig. 3 shows the TGA and DTG results for the composites. Polyester, hemicellulose, cellulose and lignin are the key organic components of the composites, which decompose or change to other carbon materials via pyrolysis. Polyester starts degrading at $250-300{ }^{\circ} \mathrm{C}$, whereas cellulose degrades at $240-350{ }^{\circ} \mathrm{C}$ with a peak at $340{ }^{\circ} \mathrm{C}$ [23]. Thermal decomposition of lignin occurs at $280-500{ }^{\circ} \mathrm{C}$ and produces many flammable organic materials. Hemicellulose decomposes within $130-194{ }^{\circ} \mathrm{C}$ [24], and is often partially removed by the alkali treatment, being hard to differentiate its degradation products from those of 
(a)

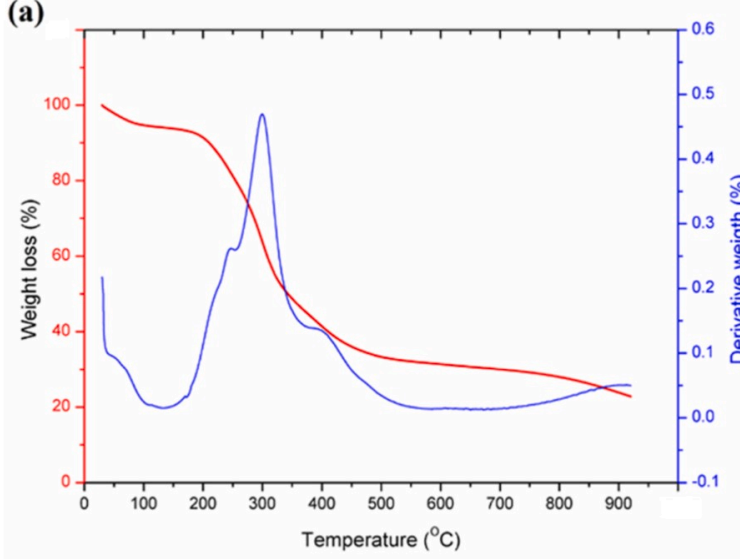

(c)

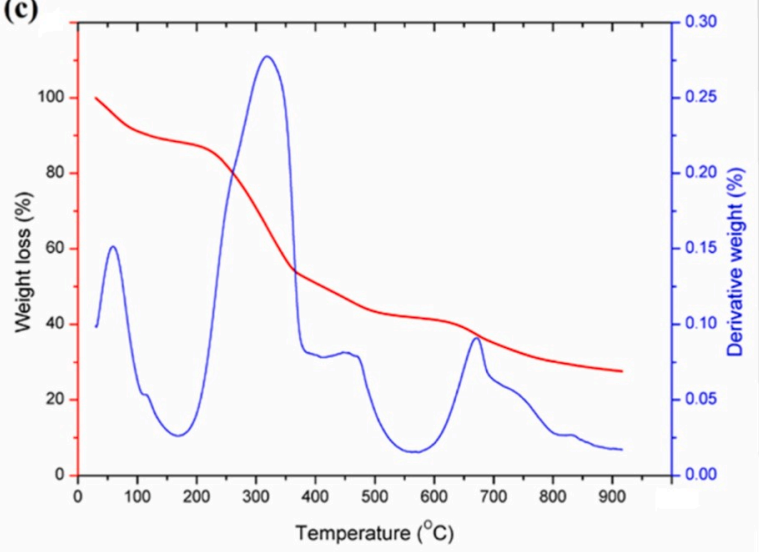

(b)

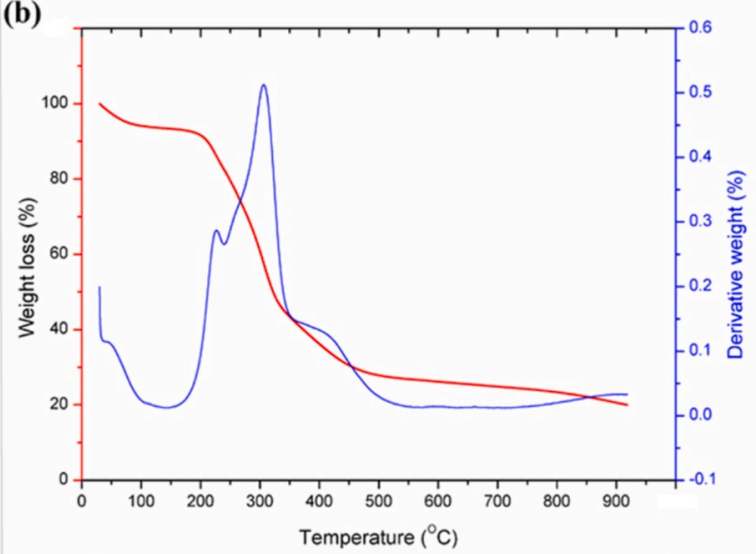

(d)

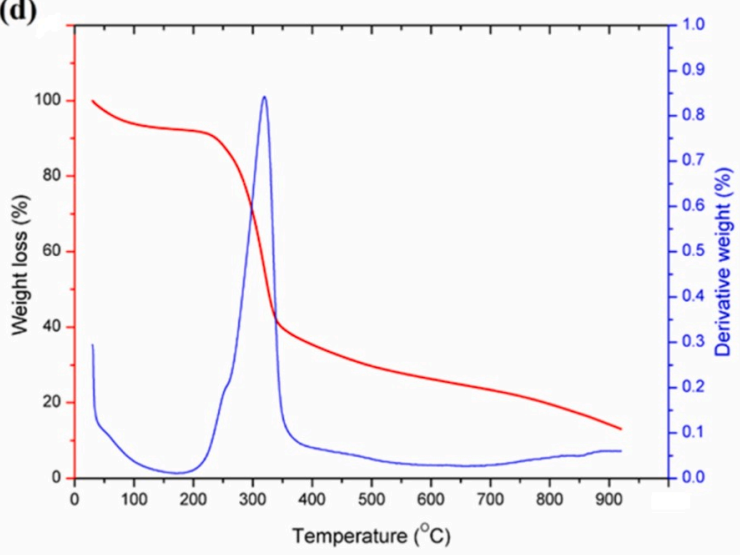

Fig. 3. TGA/DTA curves for: (a) Untreated fibre composite, (b) $\mathrm{NaOH}$ treated, (c) $\mathrm{Ca}(\mathrm{OH})_{2}$ treated and (d) tri-chloro-vinyl silane treated fibre composite.

Table 4

Results of tensile, flexural and impact tests.

\begin{tabular}{|c|c|c|c|c|c|c|}
\hline \multirow[t]{2}{*}{ Composite } & \multicolumn{2}{|l|}{ Tensile } & \multicolumn{2}{|l|}{ Flexural } & \multirow[t]{2}{*}{ Short-beam strength (MPa) } & \multirow[t]{2}{*}{ Impact Strength $\left(\mathrm{kJ} / \mathrm{m}^{2}\right)$} \\
\hline & Strength (MPa) & Modulus (MPa) & Strength (MPa) & Modulus (MPa) & & \\
\hline U3 & 22.95 & 2362 & 25.01 & 1160 & 2.86 & 15.46 \\
\hline U4 & 25.34 & 2641 & 29.99 & 1110 & 3.08 & 12.54 \\
\hline N3 & 39.76 & 2669 & 45.06 & 2270 & 4.31 & 11.69 \\
\hline N4 & 41.19 & 2174 & 43.06 & 1890 & 4.77 & 29.32 \\
\hline N5 & 46.47 & 3576 & 45.02 & 2010 & 4.31 & 10.63 \\
\hline C3 & 23.76 & 2577 & 38.43 & 2140 & 5.45 & 14.64 \\
\hline S3 & 27.47 & 1254 & 30.85 & 1290 & 7.34 & 14.71 \\
\hline S4 & 42.45 & 3447 & 50.87 & 2060 & 6.57 & 11.86 \\
\hline S5 & 40.52 & 2408 & 57.36 & 2130 & 6.42 & 15.46 \\
\hline
\end{tabular}

cellulose.

The TGA results of untreated and treated luffa/polyester composites show $5-7 \%$ mass loss at the initial stage, presumably from fibre moisture from the fibres or from residues of chemicals used in the treatment. Based on DTG, all materials showed very marginal differences, except calcium hydroxide treated composite, perhaps due to the presence of residual calcium hydroxide. Silane treated composite is more water repulsive in nature and thus displayed lower moisture content (Fig. 3d).

In most composites, major organic decomposition starts at around $200{ }^{\circ} \mathrm{C}$ and ended at $350-400{ }^{\circ} \mathrm{C}$, with minor peaks at $250{ }^{\circ} \mathrm{C}$. For the fibres with lower affinity to polyester, untreated, $\mathrm{NaOH}$ treated and, to a less extent, silane treated, the decomposition peak of the latter appeared at $250{ }^{\circ} \mathrm{C}$ in the DTG. In the case of $\mathrm{Ca}(\mathrm{OH})_{2}$ treated fibre, it overlapped with other peaks. 

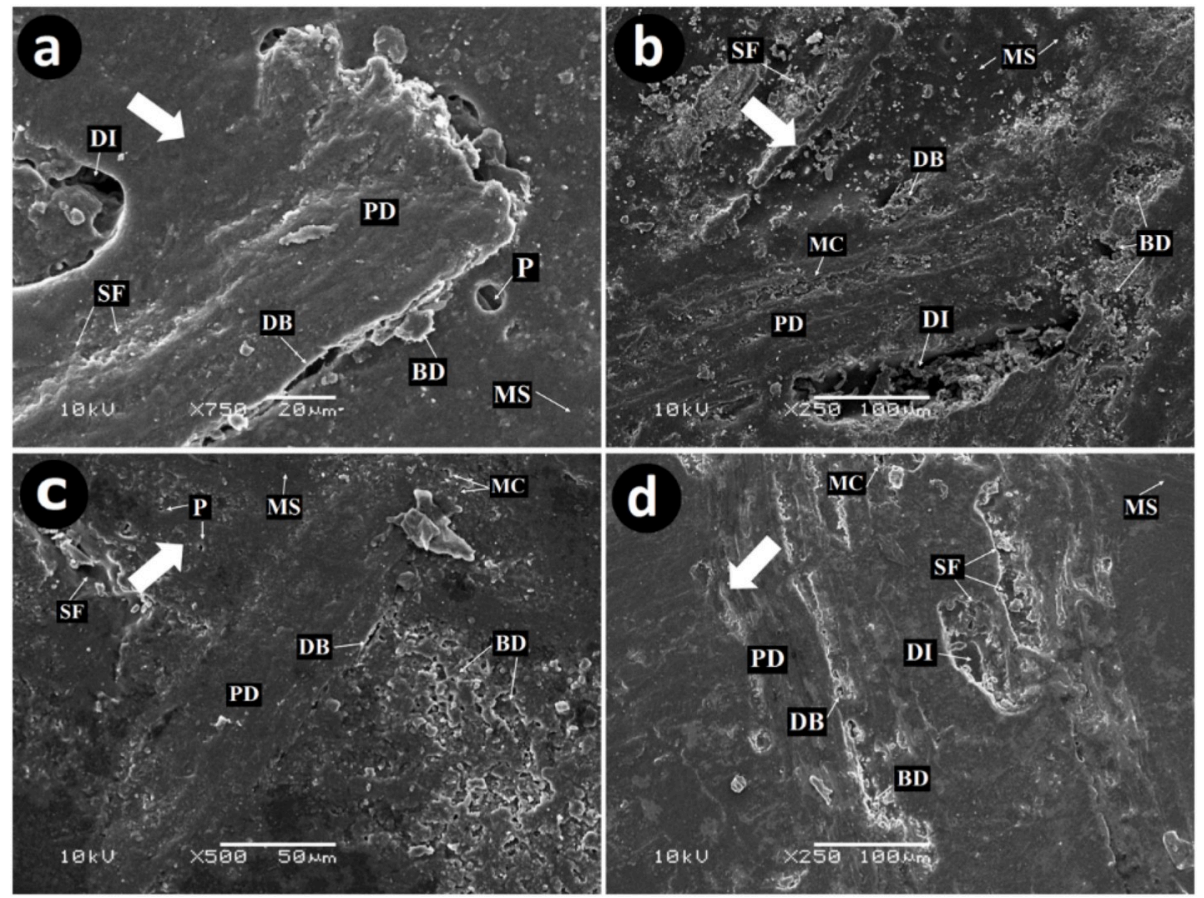

Fig. 4. SEM images of the fractured composites: Untreated (a), $\mathrm{NaOH}$ treated (b), $\mathrm{Ca}(\mathrm{OH})_{2}$ treated (c) and silane treated (d) fibres. Thick arrows indicate stress transfer direction.

Table 5

Compilation of flexural fracture mechanisms related to Fig. 4.

\begin{tabular}{|c|c|c|c|}
\hline Notation & Expansion & Narration & Reference \\
\hline $\mathrm{P}$ & Porosity & Inclusion of matrix can occur this damage during the solidification. & [25] \\
\hline MC & Micro cracks & The micro level fracture can lead by stress along axial and radial direction in composite. & {$[6,26]$} \\
\hline DI & $\begin{array}{l}\text { Damage } \\
\text { indentation }\end{array}$ & Damage occur on the composite sample surface under the indentation of during loading. & [27] \\
\hline MS & Matrix shrinkage & Shrinkage are felt in plastic deformation zones due to lower surface energy & [28] \\
\hline PD & $\begin{array}{l}\text { Plastic } \\
\text { deformation }\end{array}$ & $\begin{array}{l}\text { The wavy surface are undergone plastic flow due to the pressure developed by the asperities of loading direction. Deformed patches } \\
\text { present around the pits. }\end{array}$ & {$[27,29]$} \\
\hline $\mathrm{BD}$ & Brittle damage & Lower surface tension in matrix surfaces get damage under load. & {$[27,30]$} \\
\hline
\end{tabular}

As pointed out earlier, cellulose decomposition can be observed around $340{ }^{\circ} \mathrm{C}$ in all spectra. Besides, a wide peak appeared within $400-500{ }^{\circ} \mathrm{C}$, presumably from the decomposition of polyester and lignin polymeric materials. At around $450{ }^{\circ} \mathrm{C}$, at least $60 \%$ of the materials had decomposed. From then onwards, slow degradation is observed until around $20 \%$ residual weight, with the exception of calcium hydroxide treated fibre, due to the chemical residue that later decomposed exothermically at $680^{\circ} \mathrm{C}$ (Fig. 3c). In all, silane treated fibre composites displayed an interesting and sharp TGA curve.

The results from tensile, flexural, impact and short-beam tests are depicted in Table 4. The increase in fibre content yields higher tensile strength for all composites, and $\mathrm{NaOH}$ treated composites showed higher strength probably due to better interfacial fibre/matrix bonding. The trend in tensile modulus was generally similar.

Higher fibre content also increased flexural strength. Silane treatment yielded the highest values, followed by $\mathrm{NaOH}$ treatment. The treatments produced mostly similar flexural modulus, and all of them higher than the respective untreated composites.

Fig. 4 shows SEM images of fractured flexural test samples, where the letter codes are specified in Table 5 (compiled from references). In the untreated composites (Fig. 4a), major cracks are identified, and some minor cracks are found for the N4 composite (Fig. 4b). No apparent cracks are seen for C5 and S5 composites (Fig. 4c and d, respectively).

Table 4 also shows higher short-beam strength for the treated composites, where silane-treated fibres yielded distinctively higher values. Impact strength of the material is mainly dependent on the fibre-matrix interface, fibre treatment, construction of the material [20]. A reduction in impact strength was generally obtained for $40 \mathrm{wt} \%$ fibre content due to significant fibre-to-fibre contact.

\subsection{Dynamic mechanical analysis}

The storage modulus $\left(E^{\prime}\right)$ is a measure of the elastic response of the material. The storage modulus $\left(E^{\prime}\right)$ generally increased with the increase in fibre content. Also, E' decreases for higher temperature, especially above the glass transition temperature, due to the greater mobility of the molecules in the polymer chain [20], and the drop in storage modulus is reduced as the fibre content increased. It is observed in Fig. 5a that the 

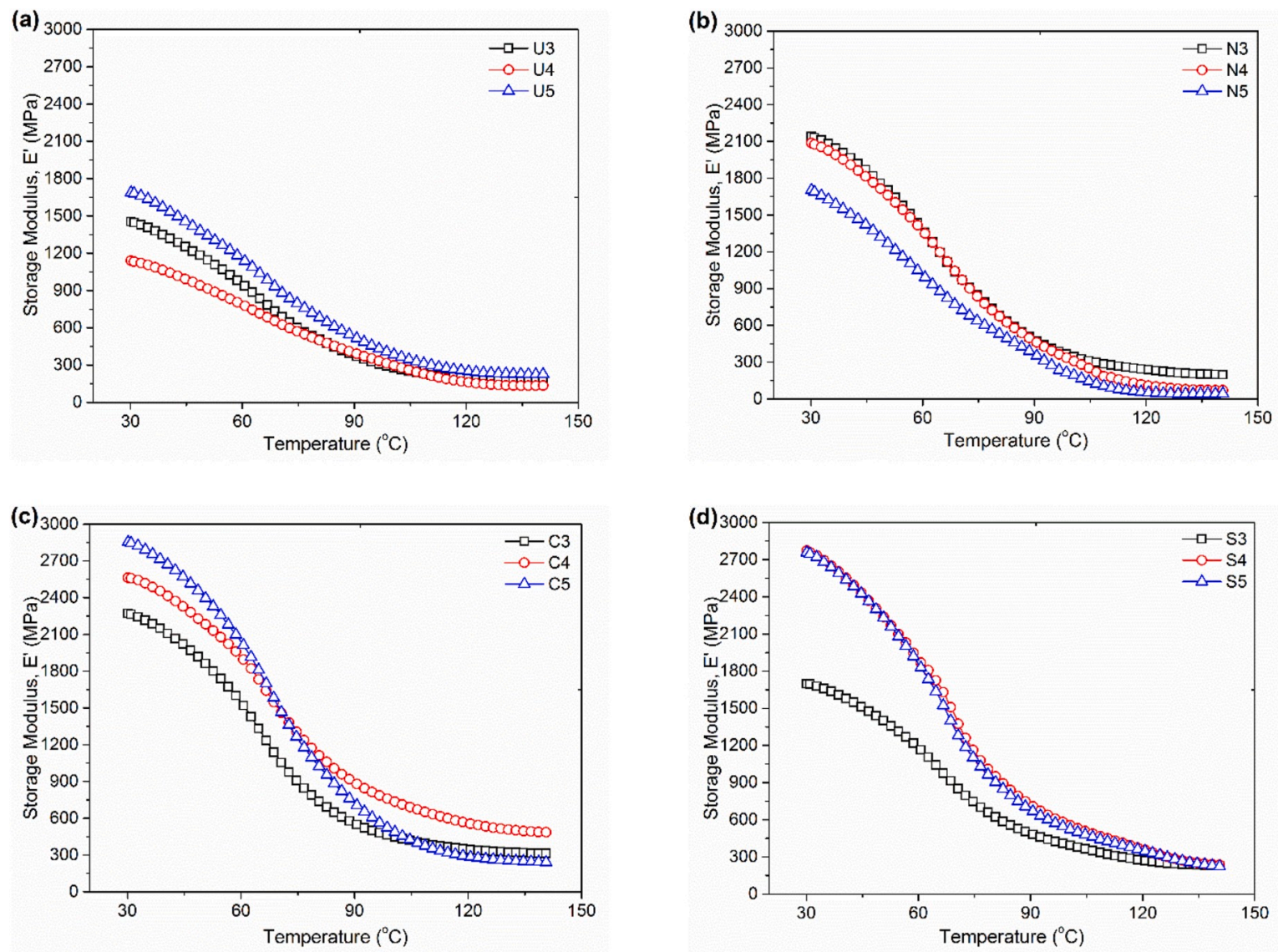

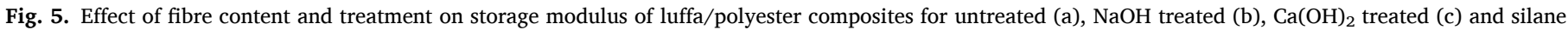
treated (d) fibers.

highest fibre content (U5) yields the highest storage modulus due to the greater restriction by the fibre on the polyester matrix and the interference of adjacent chains.

Fig. 5b reveals that storage modulus of the alkali treated fibre reinforced composite increase with fibre content. At the onset, E' is nearly $2150 \mathrm{MPa}$ for N5 composite which is nearly $40 \%$ more than the U5 composite. As a result of the surface treatment, roughness of the fibre increases, so better bonding between the matrix and fibre is established. As a result, stiffness of the composite is increased.

In the $\mathrm{Ca}(\mathrm{OH})_{2}$ composites (Fig. $5 \mathrm{c}$ ), $\mathrm{E}^{\prime}$ for $\mathrm{C} 5$ is $2850 \mathrm{MPa}$ at the initial condition, nearly $24 \%$ higher than the N5 composite. Indeed, the C5 composite shows the higher modulus among all treated and untreated composites, suggesting better compatibility between fibre and matrix. For the silane treated composite (Fig. 5d), it can be noted that S4 and $\mathrm{S} 5$ composites reached similar $\mathrm{E}^{\prime}$ values, higher than S3. Improvement in fibre-matrix compatibility and increased fibre roughness, and contact area between fibre and matrix, may also lead to tighter fibre packing. Overall, chemical treatment of the fibres produced a considerable increase in E' of the luffa fibre composites.

\subsection{Loss modulus}

Fig. 6 shows the loss modulus of the composites. In Fig. 6a, U5 composites exhibits higher loss modulus than U4 and U3 [19,20]. A peak is been seen within $75-85{ }^{\circ} \mathrm{C}$ and, above $85{ }^{\circ} \mathrm{C}$, a drastic fall in loss modulus is seen in all composites, which may be due to the weakening of the fibre and matrix interface or the decreasing in frictional resistance between them for higher temperature. The loss modulus of the composite for higher fibre content is higher in the transition region since it has to increase the internal friction which promote energy dissipation. It is observed that the U5 composite spreads over wider in the curve due to increase in rigidity of chain segments.

In Fig. 6b, the N3 composite exhibited the highest loss modulus of the $\mathrm{NaOH}$ treated composites. In addition, N3 and N4 composites showed a peak within $65-80^{\circ} \mathrm{C}$ followed by a decrease, whereas no clear peak was seen for the N5 composite, maybe due to a very poor interfacial strength of the composite from fibre agglomeration. Fig. $6 \mathrm{c}$ shows a higher peak for the C5 composite compared to C4 and C3, and Fig. 6d shows higher E" for S5 and S4.

\subsection{Damping factor}

Fig. 7 shows the effect of fibre content and treatment on damping factor for the composites. Energy dissipation depends on many factors, such as fibre structure, matrix structure, state of interface and frictional resistance at the fibre/matrix contact, fibre breakage and matrix cracking. Material systems containing more restrictions and a higher degree of reinforcement show higher $\mathrm{T}_{\mathrm{g}}$, which considerably shifted for the $\mathrm{Ca}(\mathrm{OH})_{2}$ treated fibre reinforced composites. Increase in the untreated and $\mathrm{NaOH}$ treated fibre content lowered the peak due to a 

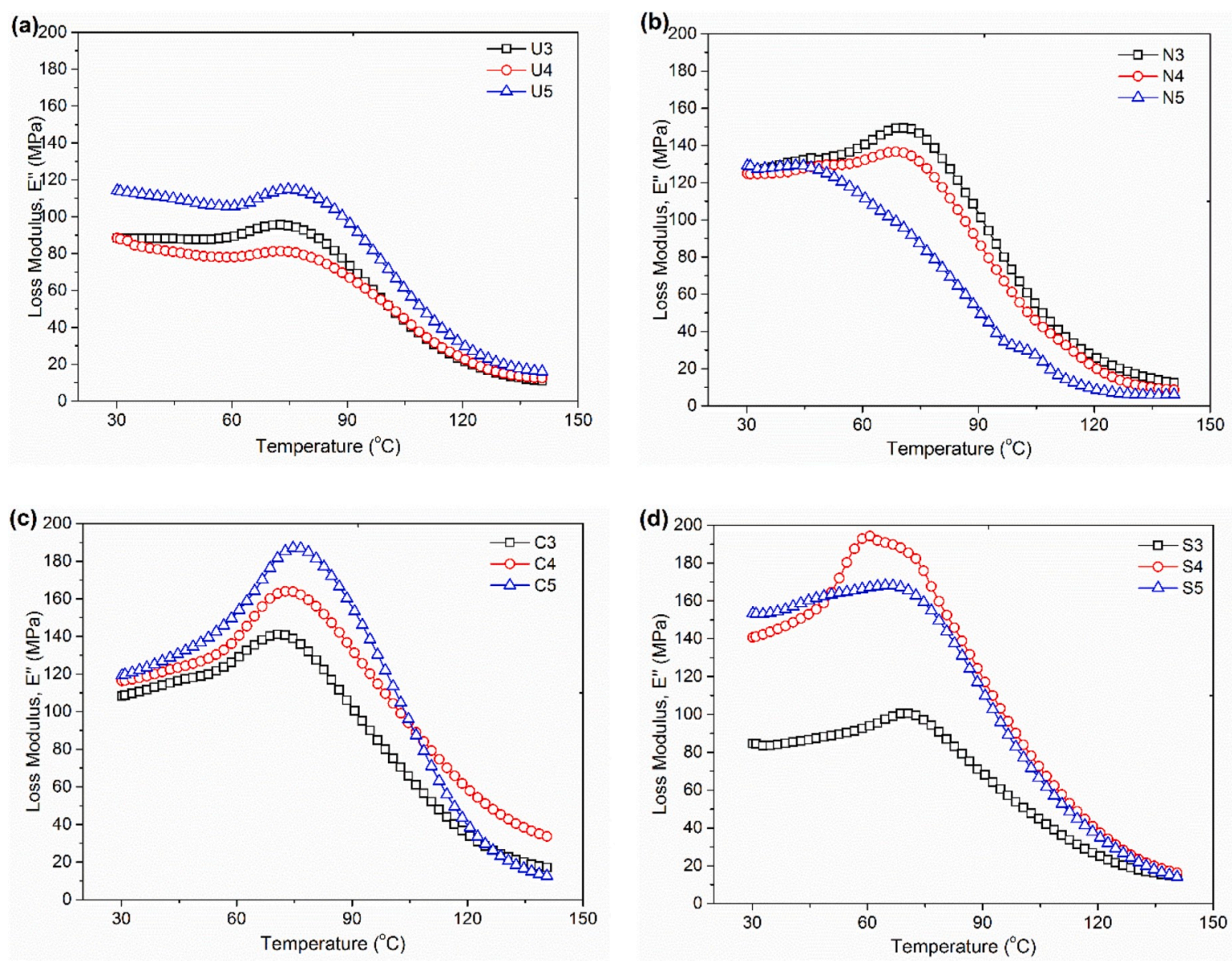

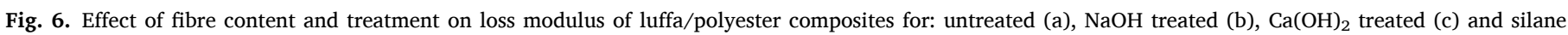
treated (d) fiber composites.

greater restriction in the polymer molecules. Table 6 shows the Glass Transition Temperature $\left(\mathrm{T}_{\mathrm{g}}\right){ }^{\circ} \mathrm{C}$ and peak value of the all composites.

Fig. 7a shows higher peak for U3 compared to U4 and U5 $[19,26]$. In Fig. 7b, peak shifts for $\mathrm{N} 4$ and $\mathrm{N} 5$ are seen, from $85{ }^{\circ} \mathrm{C}(\mathrm{N} 3)$ to nearly $115{ }^{\circ} \mathrm{C}$, which could be attributed to the increase in fibre content, indicating greater damping. Fig. 7c shows very high $\tan \delta$ value for C5 compared to C3 and C4, whereas Fig. 7d shows higher values for S4 and S5.

\subsection{Cole-Cole plot analysis}

Cole-Cole interactions express nature and structural changes of the polymer matrix of the composite. Ornaghi et al. [26] reported that, when curaua fibre content increased, Cole-Cole interaction changed from a semicircle to a more flatten shape, which was attributed to greater symmetry and good adhesion between fibre and matrix.

Fig. 8a-d shows Cole-Cole plots for the various composites of this work. Similarly, the semicircles become more flattened in all conditions. Comparing among the composites, the plots were partial semicircles for $\mathrm{Ca}(\mathrm{OH})_{2}$ (Fig. 8c) and silane (Fig. 8d) treated composites attributed to structural changes, i.e. solid state modified at this stage, which indicate good fibre-matrix interaction and homogeneity. Fibre content directly influenced mobility of molecules in the composites. The composites with the highest fibre content performed better, indicating more significant fibre/matrix interfacial adhesion.

\subsection{Theoretical modeling of storage modulus and loss factor}

Several theoretical models have been proposed for estimating the E' of composites. Those proposed by Einstein [14], Guth [15], Cohen [16] and Mooney [17] are given below:

$E_{c}=E_{m}\left(1+2.5 V_{f}\right)$

$E_{c}=E_{m}\left(1+2.5 V_{f}+14.1 V_{f}^{2}\right)$

$E_{c}=E_{m}\left(1+0.675 \rho_{c}+1.62 \rho_{C}^{2} V_{f}+14.1 V_{f}^{2}\right)$

$E_{C}=E_{m} \operatorname{Exp}\left(\frac{2.5 V_{f}}{1-S V_{f}}\right)$

where $E_{c}$ and $E_{m}$ are the storage modulus of composite and polymer matrix, respectively, $V_{f}$ is fibre volume fraction, $\rho_{c}$ is composite density, and $\mathrm{S}$ is the crowding factor assumed to be 1.35 .

Table 7 displays the theoretical and experimental $\mathrm{E}^{\prime}$ values for the untreated luffa/polyester composites at $30^{\circ} \mathrm{C}$. For $30 \mathrm{wt} \%$ fibre content, the experimental $\mathrm{E}^{\prime}$ shows better agreement with Mooney's and Guth's models. However, deviation of their predictions increased for hogher 

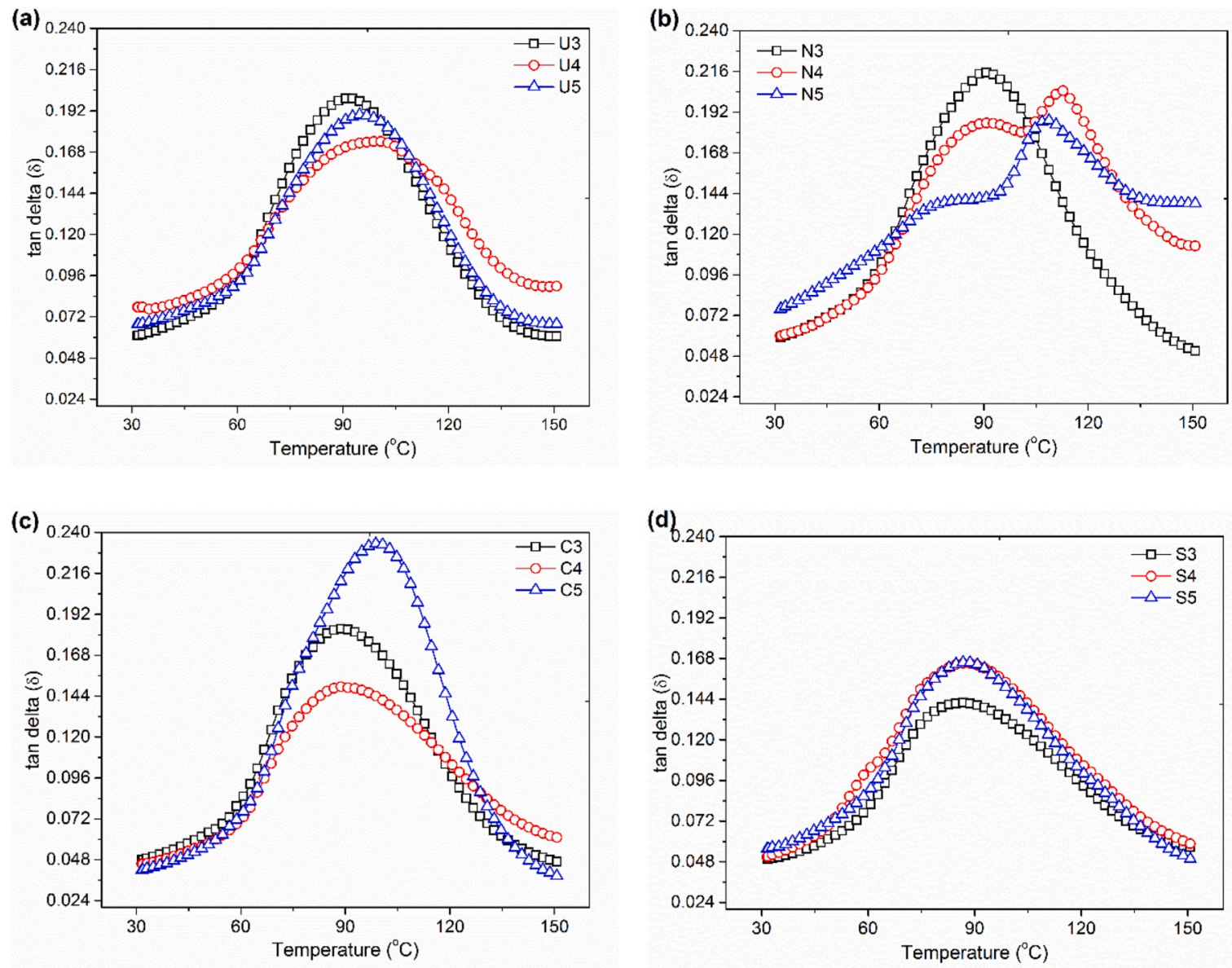

Fig. 7. Effect of fibre content and treatment on $\tan \delta$ of luffa/polyester composites for untreated (a), $\mathrm{NaOH}$ treated (b), $\mathrm{Ca}(\mathrm{OH})_{2}$ treated (c) and silane treated (d) fiber composites.

Table 6

Glass transition temperature and peak value of composites.

\begin{tabular}{|c|c|c|c|c|c|c|c|c|c|c|c|c|}
\hline Composite & U3 & U4 & U5 & N3 & N4 & N5 & C3 & C4 & C5 & S3 & S4 & S5 \\
\hline $\mathrm{T}_{\mathrm{g}}\left({ }^{\circ} \mathrm{C}\right)$ & 91.63 & 99.73 & 95.23 & 90.53 & 112.63 & 108.03 & 88.53 & 89.93 & 99.03 & 86.43 & 87.24 & 87.34 \\
\hline Peak Value & 0.20 & 0.17 & 0.19 & 0.22 & 0.21 & 0.19 & 0.18 & 0.15 & 0.23 & 0.14 & 0.17 & 0.17 \\
\hline
\end{tabular}

fibre content.

The $\tan \delta$ of the composites was estimated using two equations given by Nielsen [31]:

$\tan \delta_{c}=\operatorname{Tan} \delta_{m}\left(1-V_{f}\right)$

$\tan \delta_{c}=\tan \delta_{m}\left(1-V_{f}\right)\left(\frac{E^{\prime}{ }_{m}}{E_{c}}\right)$

where suffix $\mathrm{c}$ and $\mathrm{m}$ refer to composite and matrix, respectively.

Table 8 displays the theoretical and experimental tan $\delta$ of the untreated luffa/polyester (UT) composites with various fibre contents at $30{ }^{\circ} \mathrm{C}$. For all compositions, Nielsen model 2 showed a very good agreement with the experimental values, whereas Nielsen model 1 overestimated them.

\section{Conclusions}

The following conclusions are drawn from this work.

$>$ luffa fibre composites were successfully produced using compression moulding.

$>\mathrm{Ca}(\mathrm{OH})_{2}$ treated composites showed a considerable shift in TGA curve compared to the other treatments.

$>$ The surface treatments did not significantly affect impact strength of the composites. Higher modulus was observed for silane treated composites for all fibre contents (30\%, 40\% and 50\%). Tensile and flexural strength also showed a positive effect with treatment.

$>$ The highest tensile strength was found for the N5 composite and flexural strength for the S5 composite 

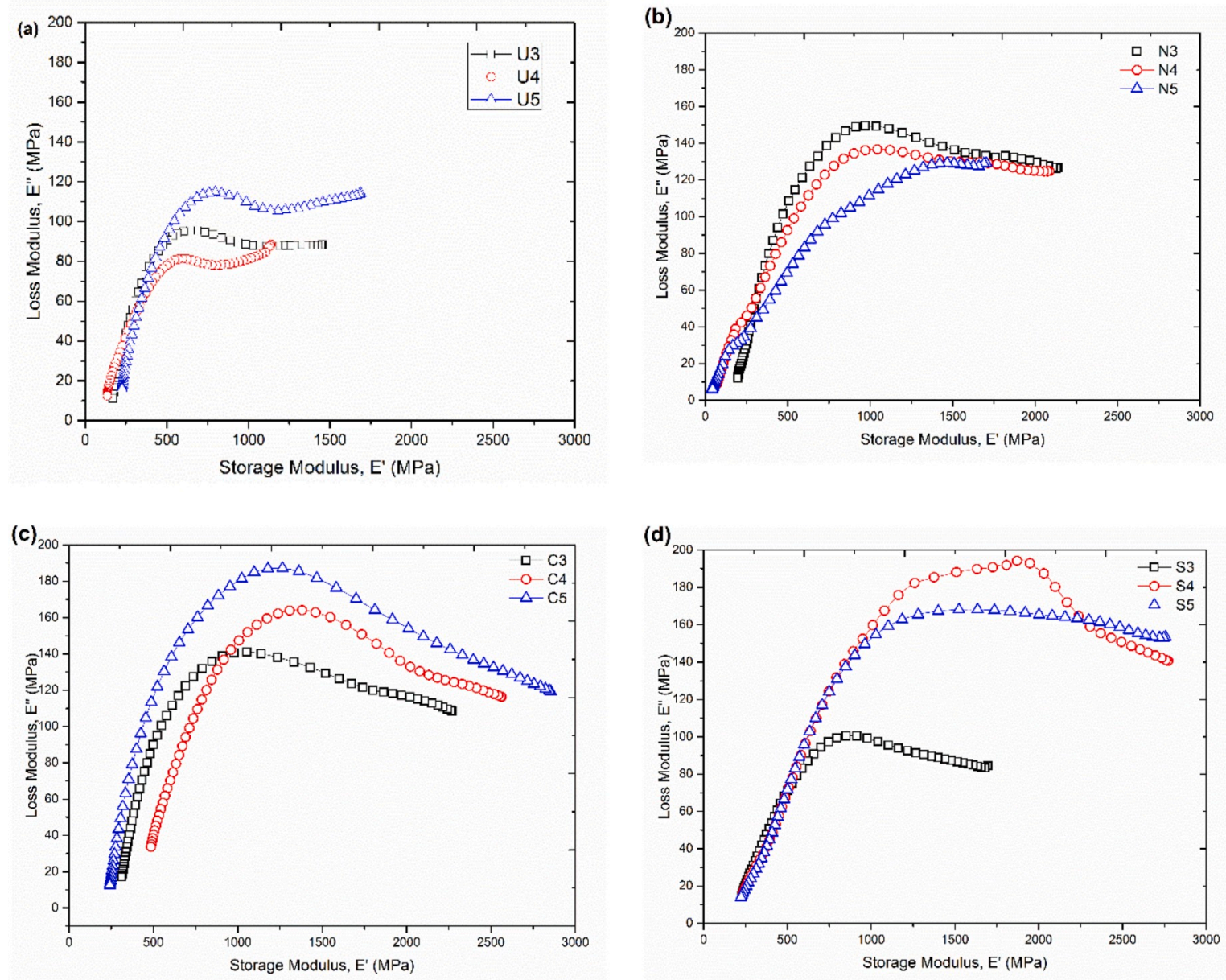

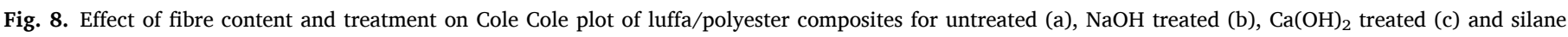
treated (d) fiber composites.

Table 7

Comparisons of theoretical and experimental E' values.

\begin{tabular}{llllll}
\hline Compositions & \multicolumn{2}{l}{ Storage modulus (E') MPa } & \\
\cline { 2 - 5 } & \multicolumn{2}{l}{ Theoretical Models } & & \\
\cline { 2 - 5 } & Einstein & Guth & Cohan & Mooney & \\
\hline U3 & 846 & 1702 & 2968 & 1612 & 1400 \\
U4 & 922 & 2388 & 3606 & 2748 & 1102 \\
U5 & 999 & 3264 & 4262 & 5914 & 1629 \\
\hline
\end{tabular}

$>\mathrm{Ca}(\mathrm{OH})_{2}$ treated composites showed higher storage modulus $(70 \%$ increased) compared to untreated composites, and higher loss modulus peak, with structural homogeneity characteristics, as inferred from the semi-circular shape of the Cole-Cole plots.

$>$ Loss modulus and damping factor found in higher manner in case of the silane treated composite.

\section{Data availability}

The raw/processed data required to reproduce these findings cannot be shared at this time as the data also forms part of an ongoing study.
Table 8

Comparisons of $\tan \delta$ predicted by theoretical models with experimental.

\begin{tabular}{|c|c|c|c|}
\hline \multirow[t]{2}{*}{ Compositions } & \multicolumn{3}{|l|}{ Loss factor $(\tan \delta)$} \\
\hline & $\begin{array}{l}\text { Theoretical Nielsen } \\
\text { model } 1\end{array}$ & $\begin{array}{l}\text { Theoretical Nielsen } \\
\text { model } 2\end{array}$ & Experimental \\
\hline U3 & 0.1830 & 0.0828 & 0.0628 \\
\hline $\mathrm{U} 4$ & 0.1593 & 0.0916 & 0.0764 \\
\hline U5 & 0.1348 & 0.0524 & 0.0690 \\
\hline
\end{tabular}

\section{CRediT authorship contribution statement}

G. Kalusuraman: Investigation, Writing - original draft. I. Siva: Conceptualization, Methodology, Writing - review \& editing. Yashwant Munde: Formal analysis, Writing - review \& editing. Chithirai Pon Selvan: Conceptualization, Supervision. S. Anand Kumar: Formal analysis, Resources. Sandro C. Amico: Methodology, Writing - review \& editing, Supervision.

\section{Acknowledgements}

The authors would like to thank CNPq, Brazil for the BJT grant and DST, India - CNPq, Brazil for the support of the India-Brazil collaboration project. 


\section{References}

[1] E. Zini, M. Scandola, Green composites: an overview, Polym. Compos. 32 (2011) 1905-1915.

[2] J.R. Araújo, W.R. Waldman, M.A. De Paoli, Thermal properties of high density polyethylene composites with natural fibres: coupling agent effect, Polym. Degrad. Stabil. 93 (2008) 1770-1775, https://doi.org/10.1016/j. polymdegradstab.2008.07.021.

[3] W. Wang, G. Huang, Characterisation and utilization of natural coconut fibres composites, Mater. Des. 30 (2009) 2741-2744.

[4] V.O.A. Tanobe, T.H.D. Sydenstricker, M. Munaro, S.C. Amico, A comprehensive characterization of chemically treated Brazilian sponge-gourds (Luffa cylindrica), Polym. Test. 24 (2005) 474-482.

[5] L. Ghali, S. Msahli, M. Zidi, F. Sakli, Effect of pre-treatment of Luffa fibres on the structural properties, Mater. Lett. 63 (2009) 61-63, https://doi.org/10.1016/j. matlet.2008.09.008.

[6] E. Laranjeira, L.H. De Carvalho, S.M. De L. Silva, J.R.M. d'Almeida, Influence of fiber orientation on the mechanical properties of polyester/jute composites, J. Reinforc. Plast. Compos. 25 (2006) 1269-1278.

[7] C. Parida, S.C. Das, S.K. Dash, Mechanical Analysis of Bio Nanocomposite Prepared from Luffa Cylindrica, vol. 4, 2012, pp. 53-59, https://doi.org/10.1016/j. proche.2012.06.008.

[8] S.K. Ramamoorthy, M. Skrifvars, A. Persson, A review of natural fibers used in biocomposites: plant, animal and regenerated cellulose fibers, Polym. Rev. 55 (2015) 107-162.

[9] N. Mohanta, S.K. Acharya, Fiber surface treatment: its effect on structural, thermal, and mechanical properties of Luffa cylindrica fiber and its composite, J. Compos. Mater. 50 (2016) 3117-3131.

[10] K. Anbukarasi, S. Kalaiselvam, Study of effect of fibre volume and dimension on mechanical, thermal, and water absorption behaviour of luffa reinforced epoxy composites, Mater. Des. 66 (2015) 321-330.

[11] A.L. da Silva, L.R.R. da Silva, I. de A. Camargo, D.L. da S. Agostini, D. dos S. Rosa D.L.V. de Oliveira, P.B.A. Fechine, S.E. Mazzetto, Cardanol-based thermoset plastic reinforced by sponge gourd fibers (Luffa cylindrica), Polímeros. 26 (2016) 21-29.

[12] N. Rajini, J.T. Winowlin Jappes, I. Siva, A. Varada Rajulu, S. Rajakarunakaran, Fire and thermal resistance properties of chemically treated ligno-cellulosic coconut fabric-reinforced polymer eco-nanocomposites, J. Ind. Textil. 47 (2017) 104-124.

[13] G. Kalusuraman, I. Siva, J.T.W. Jappes, S.A. Kumar, Effects of fiber surface modification on the friction coefficient of luffa fiber/polyester composites under dry sliding condition, J. Polym. Eng. 36 (2016) 837-846.

[14] A. Einstein, Investigations on the Theory of the Brownian Movement, Courier Corporation, 1956.

[15] E. Guth, Theory of filler reinforcement, J. Appl. Phys. 16 (1945) 20-25.

[16] L. Cohan, India rubber world, 117, 343 (1947), Rubber Chem. Technol. 23 (1950) 635.

[17] M. Mooney, The viscosity of a concentrated suspension of spherical particles, J. Colloid Sci. 6 (1951) 162-170.
[18] P.R.V. Doddi, R. Chanamala, S.P. Dora, Effect of fiber orientation on dynamic mechanical properties of PALF hybridized with basalt reinforced epoxy composites, Mater. Res. Express 7 (1) (2020) 15329, https://doi.org/10.1088/ 2053-1591/ab6771.

[19] S. Krishnasamy, C. Muthukumar, R. Nagarajan, S.M.K. Thiagamani, N. Saba, M. Jawaid, S. Siengchin, N. Ayrilmis, Effect of fibre loading and $\mathrm{Ca}(\mathrm{OH}) 2$ treatment on thermal, mechanical, and physical properties of pineapple leaf fibre/ polyester reinforced composites, Mater. Res. Express 6 (2019), 85545.

[20] G. Kalusuraman, I. Siva, J.T.W. Jappes, X.-Z. Gao, S.C. Amico, Fibre loading effects on dynamic mechanical properties of compression moulded luffa fibre polyester composites, Int. J. Comput. Aided Eng. Technol. 10 (2018) 157-165.

[21] K. Subramanian, R. Nagarajan, S. Saravanasankar, J. Sukumaran, P. De Baets, Dynamic mechanical and thermogravimetric analysis of PTFE blended tailor-made textile woven basalt-vinyl ester composites, J. Ind. Textil. 47 (2018) 1226-1240.

[22] S. Irullappasamy, R. Durairaj, S. Irulappasamy, T. Manoharan, Investigation on wear behaviors and worn surface morphology of surface treated palmyra fruit fiber/polyester composites to appraise the effects of fiber surface treatments, Polym. Compos. 39 (2018) 2029-2035.

[23] M.V.F. Ferreira, A.C.C. Neves, C.G. de Oliveira, F.P.D. Lopes, F.M. Margem, C.M. F. Vieira, S.N. Monteiro, Thermogravimetric characterization of polyester matrix composites reinforced with eucalyptus fibers, J. Mater. Res. Technol. 6 (2017) 396-400.

[24] F. Yao, Q. Wu, Y. Lei, W. Guo, Y. Xu, Thermal decomposition kinetics of natural fibers: activation energy with dynamic thermogravimetric analysis, Polym. Degrad. Stabil. 93 (2008) 90-98.

[25] V. Vilay, M. Mariatti, R.M. Taib, M. Todo, Effect of fiber surface treatment and fiber loading on the properties of bagasse fiber-reinforced unsaturated polyester composites, Compos. Sci. Technol. 68 (2008) 631-638.

[26] H.L. Ornaghi Jr., H.S.P. da Silva, A.J. Zattera, S.C. Amico, Dynamic mechanical properties of curaua composites, J. Appl. Polym. Sci. 125 (2012) E110-E116.

[27] L.U. Devi, S.S. Bhagawan, S. Thomas, Mechanical properties of pineapple leaf fiberreinforced polyester composites, J. Appl. Polym. Sci. 64 (1997) 1739-1748.

[28] S. Shibata, Y. Cao, I. Fukumoto, Study of the flexural modulus of natural fiber/ polypropylene composites by injection molding, J. Appl. Polym. Sci. 100 (2006) 911-917.

[29] A. Haneefa, P. Bindu, I. Aravind, S. Thomas, Studies on tensile and flexural properties of short banana/glass hybrid fiber reinforced polystyrene composites, J. Compos. Mater. 42 (2008) 1471-1489.

[30] J.T.W. Jappes, I. Siva, Studies on the influence of silane treatment on mechanical properties of coconut sheath-reinforced polyester composite, Polym. Plast. Technol. Eng. 50 (2011) 1600-1605.

[31] P.V. Joseph, G. Mathew, K. Joseph, G. Groeninckx, S. Thomas, Dynamic mechanical properties of short sisal fibre reinforced polypropylene composites, Compos. Part A Appl. Sci. Manuf. 34 (2003) 275-290, https://doi.org/10.1016/ S1359-835X(02)00020-9. 